\title{
FERRAMENTAS DE ABORDAGEM FAMILIAR: UMA EXPERIÊNCIA DO CUIDADO MULTIPROFISSIONAL NO ÂMBITO DA ESTRATÉGIA SAÚDE DA FAMÍLIA
}

\author{
Kaiza Katherine Ferreira SANTOS ${ }^{1}$ \\ Camila Rodrigues de FIGUEIREDO² \\ Keyla Marinho de PAIVA ${ }^{3}$ \\ Ludmilla Rodrigues CAMPOLINA4 \\ Andra Aparecida Dionízio BARBOSA5 \\ Aline Soares Figueiredo SANTOS6
}

\begin{abstract}
1-Cirurgiã-dentista. Especializanda da Residência Multiprofissional em Saúde da Família. Universidade Estadual de Montes Claros. E-mail: kaizaferreiraa@hotmail.com

2-Enfermeira. Especializanda da Residência Multiprofissional em Saúde da Família. Universidade Estadual de Montes Claros. E-mail: camila.enfmoc@gmail.com

3-Cirurgiã-dentista. Especialista em Saúde da Família. Universidade Estadual de Montes Claros. E-mail: keylamarinho@hotmail.com

4-Enfermeira. Especialista em Saúde da Família. Universidade Estadual de Montes Claros. E-mail: ludicampolina@gmail.com

5-Enfermeira. Docente da Residência Multiprofissional em Saúde da Família. Universidade Estadual de Montes Claros. E-mail: andrabh@ hotmail.com

6-Cirurgiã-dentista. Mestre em Ciências da Saúde. Universidade Estadual de Montes Claros. E-mail: alinesfigueiredos@yahoo.com.br
\end{abstract}

\section{Recebido em: 04/05/2015 - Aprovado em: 29/08/2015 - Disponibilizado em: 30/10/2015}

Resumo: O trabalho da Estratégia Saúde da Família tem como foco a família, considerando-a como lócus básico de atuação, as técnicas usadas para tanto devem basear-se na realidade local construindo um fazer consistente que implique na melhoria da qualidade de vida da população e dos indicadores de saúde. Este estudo tem por objetivo realizar um estudo de caso sobre uma família residente na área de abrangência da Estratégia Saúde da Família Esplanada II, na cidade de Montes Claros/MG, com enfoque na aplicação das ferramentas de abordagem familiar Genograma, Ecomapa, Ciclo de Vida, F.I.R.O, P.R.A.C.T.I.C.E. e Conferência familiar, como meio de vínculo e aproximação da família, em especial das que requerem um olhar especial da equipe de saúde por sua maior vulnerabilidade e conflitos. A utilização de tais ferramentas possibilitou aprofundamento do conhecimento da família como um todo e da dinâmica de funcionamento familiar. Em relação à família, destaca-se a melhoria da qualidade de vida e saúde da família, fortalecimento dos vínculos entre seus membros e a definição de papéis para melhor funcionamento da dinâmica familiar.

Palavras-chave: Atenção á Saúde. Atenção Primaria á Saúde. Estratégia Saúde da Família. Relações Familiares. Relações Profissional-Família.

\begin{abstract}
The work of the Family Health Strategy is focused on the family, considering it as a basic locus of action, the techniques used for both should be based on local realities building a consistent making involving the improvement of people's quality of life and health indicators. This study aims to conduct a case study of a family residing in the area covered by the Family Health Strategy Terrace II in the city of Claros / MG Montes, focusing on the application of the familiar approach of tools Genogram, FIRO P.R.A.C.T.I.C.E. and Life Cycle as a means of bonding and closeness of the family, especially those requiring a special look of the health team because of their vulnerability and conflict. The use of such tools allowed deepening the knowledge of the family as a whole and family functioning dynamics. In relation to the family, there is the improvement of quality of life and family health, strengthening the links between its members and the definition of roles for the better functioning of the family dynamics.
\end{abstract}

Keywords: Health care. Primary Health Care. Family Health Strategy. Family Relations. Professional-Family Relations. 


\section{INTRODUÇÃO}

A Estratégia Saúde da Família (ESF) surge no Brasil, em 1994, como uma estratégia de reorientação do modelo assistencial a partir da atenção básica, em conformidade com os princípios do Sistema Único de Saúde (SUS) como universalização, equidade, integralidade, descentralização, hierarquização e participação da comunidade. Prioriza ações de proteção à saúde e promoção da qualidade de vida e intervenção nos fatores que a colocam em risco (ROSA; LABATE, 2005; BRASIL, 1997).

O trabalho da ESF tem como foco a família, considerando-a como lócus básico de atuação, as técnicas usadas para tanto devem basear-se na realidade local construindo um fazer consistente que implique na melhoria da qualidade de vida da população e dos indicadores de saúde (WAGNER et al., 2001).

Segundo Minuchin (1985) a família é um complexo sistema de organização, com crenças, valores e práticas concordantes com as mudanças da sociedade, que busca a melhor adaptação possível para sobrevivência de seus membros. O sistema familiar sofre mudanças à medida que a sociedade muda e isso pode gerar pressões internas e externas que fazem com os seus membros se modifiquem com a finalidade de assegurar a continuidade do bem estar psicossocial de seus membros.
Com isso focando a atuação na família, amplia-se a noção de atendimento integral à saúde, em que, a partir de um cliente, as ações são desdobradas para o grupo, com a organização de práticas preventivas coletivas e de promoção de saúde (PUPULIN et al., 2003).

A equipe multiprofissional de saúde é levada a conhecer a realidade das famílias pelas quais é responsável, por meio do cadastramento e da identificação de suas características, tornando-se mais sensível às suas necessidades. Assim, esses profissionais e a população acompanhada criam vínculos, o que facilita a identificação e o atendimento dos problemas de saúde da comunidade (BRASIL, 1997). Para alcançar esses objetivos, com um cuidado em saúde que alcance resultados satisfatórios e seja eficaz no cuidado à família, faz-se necessário a utilização das ferramentas de família.

As ferramentas de trabalho com famílias são tecnologias relacionais que tem por objetivo estreitar as relações entre a família e o profissional de saúde, possibilitando assim, conhecer o indivíduo em sua singularidade, bem como sua relação com a família e a comunidade (SILVEIRA FILHO, 2007).

O trabalho com a família deve envolver um completo entendimento e uma extensa avaliação clínica e psicológica de seus membros, para tanto é necessário à utilização 
de ferramentas de abordagem familiar, que facilitarão a compreensão na formulação de um diagnóstico que possibilitará uma intervenção eficiente. Dentre as várias ferramentas existentes, tem-se: o Genograma; Ecomapa; Ciclo de vida; P.R.A.C.T.I.C.E ; F.I.R.O e por fim, a Conferência Familiar.

Assim, este estudo tem por objetivo realizar um estudo de caso sobre uma família residente na área de abrangência da Estratégia Saúde da Família Esplanada II, na cidade de Montes Claros/MG, com enfoque na aplicação das ferramentas de abordagem familiar como meio de vínculo e aproximação da família.

\section{RELATO DE CASO}

A família em estudo é composta pela paciente índice Maria, sua mãe Teresa, seu sobrinho Marcos e o seu irmão Paulo. A casa onde residem possui 3 quartos, 1 sala, 1 cozinha, banheiro, garagem e quintal. Ao lado da casa tem um cômodo que funciona como salão de beleza do sobrinho e se comunica com a garagem da casa.

Maria 58 anos, solteira, nega patologias pessoais, religião protestante, aposentada, cuidadora principal da mãe. Teresa, 79 anos, mãe de Maria, proprietária da casa, é portadora de DPOC (Doença Pulmonar Obstrutiva Crônica) encontra-se em oxigenoterapia domiciliar, é hipertensa, alérgica e desenvolveu quadro de demência, foi casada com Silvio, falecido, em 2013, aos 87 anos de Infarto Agudo do Miocárdio (IAM), com quem teve três filhos: Maria, Paulo e Ana. Paulo, 60 anos, é viúvo e possui dois filhos está em tratamento para tuberculose (TBC), sofreu AVC, é portador de hipertensão e possui artrite, passa a maior parte do tempo, quando se encontra em casa, o que esporadicamente acontece, em seu quarto nos fundos da casa. Marcos, 33anos, foi criado pelos avós, solteiro, possui um filho de três anos, trabalha como cabeleireiro em um ponto de comércio ao lado da casa onde residem, demonstra instabilidade emocional e comportamental, sugerindo quadro psiquiátrico de transtorno delirante persistente, já esteve sob tratamento psicológico e psiquiátrico, recebeu oferta de acompanhamento em psicoterapia, mas não compareceu ao atendimento. Toda a família faz acompanhamento em um centro de especialidades para tratamento de TBC.

A família encontra-se em conflito, especialmente, devido à incapacidade de lidar com questões relacionadas à condição clínica de Teresa, sua fragilidade e dependência para realizar atividades de vida diária o que requer um empenho de seus familiares, entretanto observa-se uma sobrecarga de trabalho e responsabilidades para Maria que refere privar-se de socializar-se e cuidar de si para dedicar-se exclusivamente aos cuidados de 
sua mãe, denota uma instabilidade emocional e insatisfação com a situação vivenciada. Maria também possui uma relação desarmoniosa e não consegue manter diálogo e estabelecer vínculo com Marcos e Paulo, brigas são frequentes. Os membros da família discordam quanto à responsabilidade de cada um frente aos cuidados necessários à idosa. A família demonstra desgaste físico e emocional e um relacionamento comprometido.

A família foi denunciada junto ao Conselho Municipal de Idoso pelos constantes episódios de violência verbal e devido à falta de auxilio familiar à idosa. Após as denúncias a família passou ser acompanhada por uma assistente social do CRAS - Centro de Referencia de Assistência Social.

A pesquisa foi conduzida dentro dos padrões exigidos pela declaração de Helsinki e aprovada pelos Comitês de Ética em Pesquisa da Universidade Estadual de Montes Claros recebendo parecer 572.244 de 27/03/2014. Os participantes consentiram em participar do estudo por meio do Termo de Consentimento Livre e Esclarecido (TCLE). Foi garantido sigilo e anonimato das informações. Os nomes utilizados foram fictícios para preservar a identidade dos participantes.

\section{RESULTADOS E DISCUSSÃO}

A utilização das ferramentas de abordagem familiar possibilita à equipe de saúde a construção de um conhecimento mais abrangente acerca da família em questão e uma interação maior com a mesma no sentido de melhorar a relação de ajuda estabelecida entre profissionais e membros do conjunto familiar (NOBRE et al; 2014).

O presente estudo de caso teve como ponto de partida a demanda trazida pelo Agente Comunitário de Saúde (ACS) da necessidade de realizar visita domiciliar à família em estudo, com enfoque na saúde frágil da idosa e os constantes conflitos familiares. A Equipe multiprofissional acolheu essa demanda e após as visitas domiciliares seguiu-se com o estudo dessa família. Embora a demanda inicial fosse em decorrência da saúde frágil de Teresa Observou-se no decorrer das visitas que a cuidadora e a chefe da família Maria seria a paciente índice do caso devido sua sobrecarga de cuidado e condição emocional.

O genograma da família de Maria nos permite uma visualização rápida com informações relevantes com relação à família, para um melhor conhecimento da mesma. Segundo CHAPADEIRO et al., (2012) o genograma é uma ferramenta de representação gráfica da família por meio da qual são representados cada um dos seus membros, seus relacionamentos e as morbidades, podendo ainda ser acrescentadas outras informações relevantes como escolaridade e hábitos. 
O Ecomapa é uma ferramenta que complementa o genograma, pois é a representação da rede social da família e envolve as relações intrafamiliares e com o meio externo, são o suporte da família (CHAPADEIRO; ANDRADE; ARAÚJO, 2012). A família em estudo possui uma relação com o meio social e externo de suporte prejudicado, com um vínculo superficial com o trabalho, amigos, serviço social e Igreja, e uma relação de proximidade com o serviço de saúde como retratado no Ecomapa.

Figura 1- Genograma da Família do estudo de caso. ESF.Esplanada II, Montes Claros, MG. Dezembro de 2014.

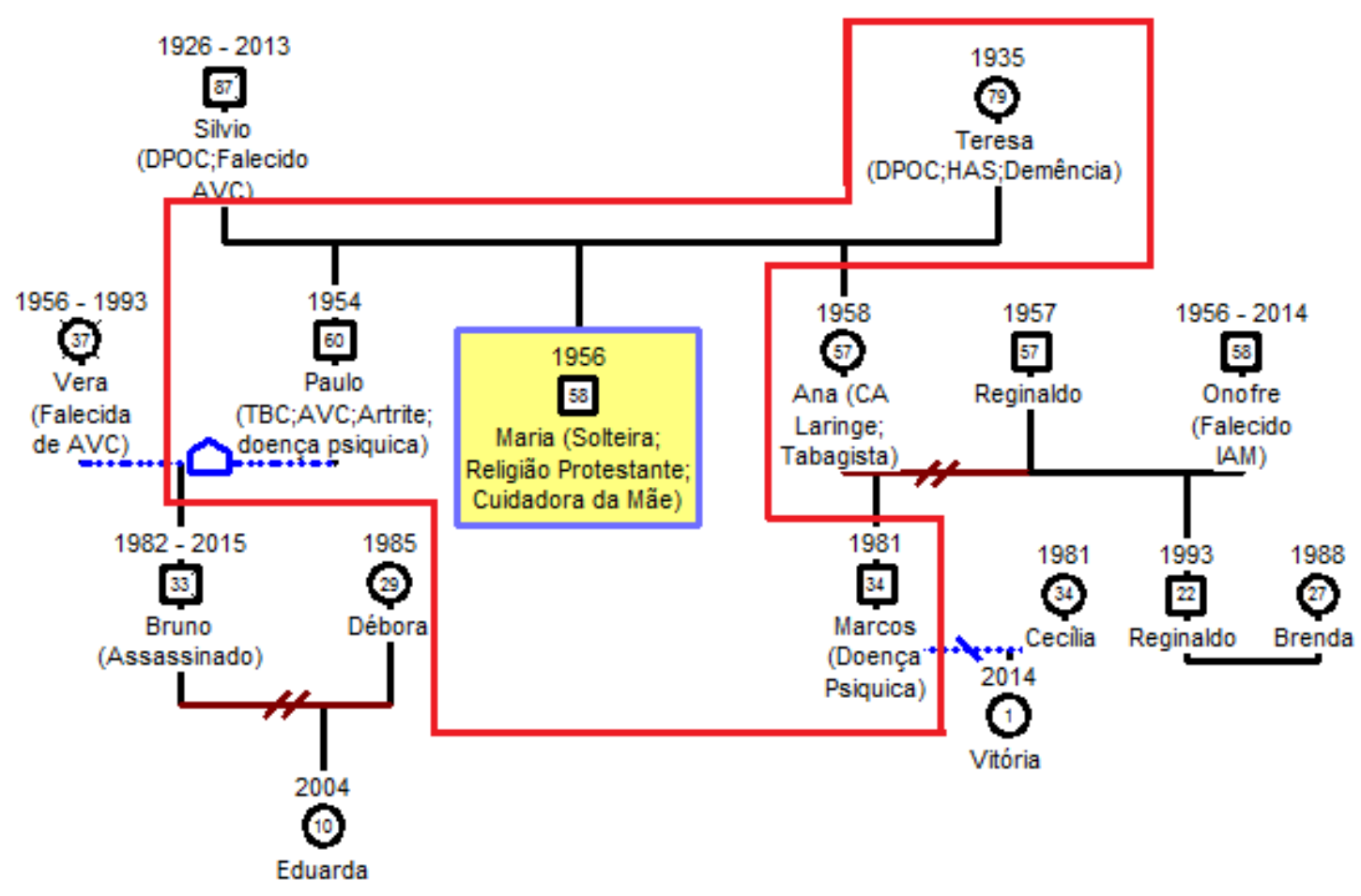

Legenda
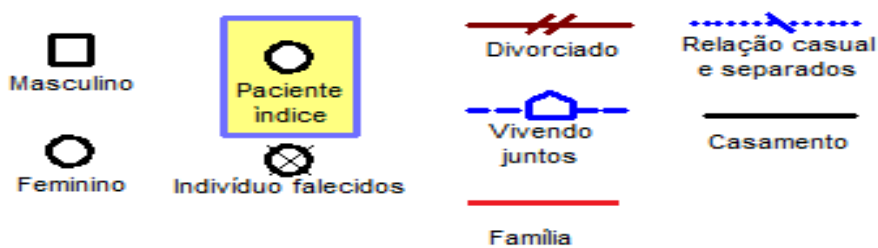

Fonte: Confeccionado pelos autores 
Figura 2- Ecomapa da Família do estudo de caso. ESF.Esplanada II, Montes Claros, MG. Dezembro de 2014.

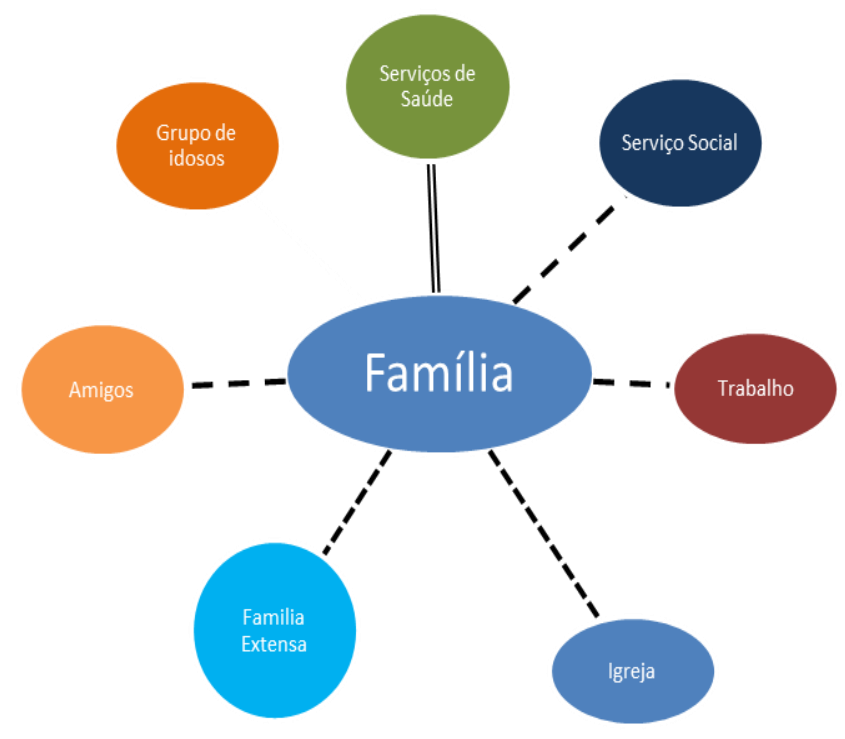

Fonte: Confeccionado pelos autores.

O ciclo de vida é uma ferramenta que divide a história da família em estágios de desenvolvimento (jovens adultos saindo de casa; casamento; famílias com filhos pequenos; famílias com filhos adolescentes; lançando os filhos e seguindo em frente; famílias em estágio avançado de vida), caracterizados por tarefas específicas e crises evolutivas e/ou previsíveis, que exigem adaptações e ajustamentos de seus membros (MOYSÉS, 2003). A família do estudo apresenta como fase do ciclo de vida dominante o estágio que abrange a Família em processo de envelhecimento, os seus membros passam por dificuldade para administrar as tarefas específicas dessa fase, bem como as crises específicas e não conseguem assumir seus papéis o que esta gerando disfunções familiares.

As orientações fundamentais das relações interpessoais, F.I.R.O, é uma ferramenta que tem por objetivo avaliar os sentimentos dos membros da família na vivência das relações cotidianas (CHAPADEIRO; ANDRADE; ARAÚJO, 2012).

Aplicamos junto a família a ferramenta de acesso à família F.I.R.O que envolve as dimensões: inclusão (estrutura, conectividade e modo de compartilhar), controle (dominante, colaborativo e reativo) e intimidade. Em inclusão, percebe-se na estrutura que os membros da família não conseguem estabelecer diálogo. Eles passam 
muito tempo sem se falar e quando se comunicam o fazem em tons de voz elevados e com xingamentos. $\mathrm{Na}$ conectividade existem laços afetivos frágeis entre os membros, que não conseguem assumir seus papéis no cuidado a mãe idosa frágil o que interfere no autocuidado.

Em modos de compartilhar percebe-se que a família não se reúne para discutir os problemas da família o que gera sobrecarga na cuidadora Maria. No contexto familiar apenas Teresa tem relação íntima com a religião, entretanto todos os membros da família raramente frequentam a igreja. $\mathrm{Na}$ esfera controle observa-se Maria como dominante, pois ela direciona as conversas e resolve todos os problemas da família, mas se sente sobrecarregada com essa função.

$O$ controle reativo se enquadra na figura de Paulo e, principalmente, Marcos que frequentemente questiona Maria sobre atitudes e decisões tomadas frente aos problemas da família, em especial com relação ao cuidado de Teresa. Todos os membros da família discordam entre si. Não há controle colaborativo na família em questão. No tópico intimidade, verificou-se ausência de demonstração de carinho e qualquer forma de afeto como beijos e abraços entre os familiares.

O P.R.A.C.T.I.C.E é um instrumento que permite a avaliação do funcionamento das famílias, ele facilita a coleta de informações e entendimento do problema, seja ele de ordem clínica, comportamental ou relacional (CHAPADEIRO et al., 2012; MOYSÉS; SILVEIRA FILHO, 2002). O P.R.A.C.T.I.C.E também foi aplicado, onde analisamos cada componente: $\mathrm{o} \quad \mathrm{P}$ ou Presenting Problem (Problema apresentado ou razão da entrevista), foi identificado conflitos familiares relacionados aos cuidados com a mãe que é idosa frágil. Os membros da família discordam da conduta de cada um frente ao cuidado de Teresa e a forma de viver e relacionar de cada membro.

A família foi denunciada junto ao Conselho do Idoso pelos episódios frequentes de violência verbal e devido à falta de auxilio familiar à idosa. Em R ou Roles and Structure (Papéis e estrutura) percebeu-se que os membros não tem uma divisão de funções não conseguem assumir seus papéis familiares, sobrecarregando Maria com cuidados, esta é responsável por prover a família economicamente, com auxilio da irmã Ana que não reside na mesma casa e aposentadoria de Maria.

$$
\text { Referente a A ou Affect (Afeto) }
$$
constatou-se que Maria demonstra-se insatisfeita por não conseguir retomar sua vida social, voltar a trabalhar e retomar seus laços de amizade, sair de casa com os amigos. Após a morte de Silvio, seu pai, há dois anos, houve piora do quadro de saúde de Teresa, e 
consequentemente, Maria não conseguiu organizar sua vida pessoal, desde então há grande expectativa dos familiares para com esta na resolução dos problemas familiares e administração financeira da família. Foi observada oscilação de emoções: calmaria, nervosismo, tristeza, raiva.

Em relação a $\mathrm{C}$ ou Communication (Comunicação) verificou-se dificuldade no diálogo familiar. Paulo não foi encontrado durante as visitas à família, e dificilmente, encontra-se em casa. Marcos recusa-se a dialogar com a equipe da ESF, possui doença psíquica, recebeu oferta de acompanhamento em psicoterapia pela ESF, mas não compareceu ao atendimento. Ana reside em outro estado e mantêm comunicação com a família apenas por contato telefônico.

Em T ou Time in the family life cycle (Tempo no ciclo de vida familiar) predomina na família o ciclo de vida familiar: família envelhecendo. No tópico I ou Illness in family past and present (Enfermidade na família no passado e no presente) certificou-se Silvio possuía DPOC e foi fumante. Teresa possui a DPOC e consequentemente foi fumante passiva durante muitos anos. Maria se sente preocupada com o quadro de Teresa e tenta a cooperação de toda a família para melhora a qualidade de vida de Teresa.

Quanto a C ou Coping with Stress (Enfrentando o estresse) observou-se dificuldade dos membros em assumir seu papel na família e não há uma divisão de tarefas nos cuidados com Teresa e das atividades domésticas, o que resulta em sobrecarga de trabalho para Maria. A família não busca apoio na comunidade. Não acontecem momentos recreativos, diálogos frequentes e uso de recursos sociais. Em E ou Ecology (Ecologia) Maria e sua família sempre procuram a ESF para os cuidados com a saúde, com frequência por meio de visitas domiciliares da equipe multiprofissional. Eles recebem visitas dos membros da igreja e raramente de amigos. O serviço do Centro de Referência de Assistência Social (CRAS) foi acionado por vizinhos para ajudar nos conflitos familiares.

A ferramenta P.R.A.C.T.I.C.E, que organiza informações obtidas com a família e facilita sua avaliação, e que pode ser relacionada a questões médicas, comportamentais e de relacionamento cumpriu com seu propósito. Constatou-se na sua aplicação, quanto à dinâmica familiar, a dificuldade de lidar com os problemas familiares e da existência na família de membros com sobrecarga de trabalho. Em acréscimo a isso se comprovou que as relações familiares giram em torno da dependência da paciente índice, Maria.

A conferência familiar corresponde a uma forma estruturada de intervenção na família, que deve sempre respeitar os objetivos já anteriormente apresentados. É 
uma reunião com plano previamente acordado entre os profissionais presentes e em que, para além da partilha da informação e de sentimentos, se pretende ajudar a mudar alguns padrões de interação na família (NETO, 2003).

Após aplicação das ferramentas a equipe utilizou-se a Conferência Familiar. Ela foi realizada no domicílio da família. No primeiro momento foi realizada uma préconferência na qual foi estabelecido o horário da realização da conferência e identificados familiares para participarem.

A realização da conferência familiar contou com uma equipe multiprofissional. Estiveram presentes além da equipe, Maria, Teresa e Marcos, Paulo foi convidado a participar da conferência, entretanto, nas três tentativas realizadas, não compareceu. Iniciou-se com breve apresentação da equipe e participantes e foram pontuados os objetivos da realização da conferência, seguida da exposição dos problemas familiares levantados: conflitos familiares; sobrecarga de trabalho sobre um membro da família; dificuldade de retomar a vida social após ter abandonado a vida pessoal para se tornar cuidadora; e falta de diálogo entre os membros da família. Durante a discussão foram abordados os papéis que cada membro vinha desempenhando na família e quais os sentimentos advindos desse papel, sempre valorizando seus sentimentos e expectativas.
Foi aberto um momento para que cada um expressasse seu ponto e vista acerca da situação vivenciada e para tomada de decisão. A paciente índice levantou propostas para rearranjo familiar quanto cuidados da mãe. Por fim, foi acordado que Maria retomaria suas atividades pessoais, como ir à igreja e sair com os amigos e Marcos se responsabilizaria com os cuidados de Teresa nessas situações e esta comprometeu-se a ser mais colaborativa, como dormir na cama à noite, o que era feito no sofá e incomodava os familiares.

Após a conferência foi realizada uma pós conferência para analisar se a nova dinâmica familiar com redistribuição de tarefas havia resultado em resolução efetiva dos problemas levantados. Notamos que houve uma melhoria do relacionamento de Maria com Marcos, ela conseguiu sair algumas vezes e o sobrinho ficou com a idosa. A idosa não conseguiu dormir na cama e surgiram novos problemas. Percebeu-se a necessidade de acompanhamento psicológico de Marcos e um quadro demencial de Teresa e dificuldade de dormir.

Houve a necessidade de realizar nova visita à família para discutir cuidados com o idoso, embasados no Guia Prático do Cuidador dialogamos de maneira simples e ilustrativa sobre os principais tópicos desse guia, com foco no envolvimento da família no cuidado domiciliar. A avaliação médica 
denotou-se a necessidade de reajuste da medicação com acréscimo de novo fármaco: Haloperidol. Em outra oportunidade a educadora física foi convidada a acompanhar a equipe de saúde em uma visita à família para ensinar movimentos de alongamento para Maria e Teresa, contribuindo assim, com a promoção da melhoria da qualidade de vida da cuidadora e da pessoa que é cuidada.

\section{CONSIDERAÇÕES FINAIS}

A realização deste estudo tornou-se relevante, pois mostrou que trabalhar com famílias constitui uma ação desenvolvida por meio da compreensão e exploração das estruturas familiares, com o intuito de elaborar uma estratégia personalizada a cada conjunto familiar, sendo isto possível com o uso das ferramentas de acesso.

Com o uso das ferramentas na abordagem familiar conseguimos um aprofundamento do conhecimento da família como um todo e da dinâmica de funcionamento familiar. Em relação à família, destaca-se a melhoria da qualidade de vida e saúde da família, fortalecimento dos vínculos entre seus membros e a definição de papéis para melhor funcionamento da dinâmica familiar.

Ressalta-se que uso das ferramentas permite ao profissional da atenção básica estabelecer um vínculo com a família, pois, ao dar atenção, facilita ser aceito para investigar e intervir, obtendo a satisfação não só da população atendida, como também da equipe que executa a proposta.

\section{REFERÊNCIAS}

1-CHAPADEIRO C.A.; ANDRADE H.Y.S.O; ARAÚJO M.R.N. A família como foco da atenção primária à saúde. Belo Horizonte: nescon/UFMF; 2012.

2-ISABEL GALRIÇA NETO. A conferência familiar como instrumento de apoio á família em cuidados paliativos. Revista Portuguesa de clínica geral, 2003, 19:58-74.

3-MINUCHIN, P. Families and individual development: provocations from the field of family therapy. Child Development. 1985; v. 56: p. 289-302.

4-MOYSÉS, S. J.; SILVEIRA FILHO, A. D. Os dizeres da boca em Curitiba: boca maldita, boqueirão, bocassaudáveis. Rio de Janeiro: CEBES; 2002: p. 155-60.

5-NOBRE, L.L.R; et al. Abordagem familiar no âmbito da Estratégia Saúde da Família: Uma Experiência de cuidado interdisciplinar. Revista da Universidade Vale do Rio Verde, Três Corações. ago./dez. 2014, v. 12, n. 2, p. 458-468.

6-PUPULIN, A. R. T. et al. Acompanhamento domiciliar de pacientes chagásticos tratados etiologicamente. Revista Brasileira de Análise Clínica. Rio de Janeiro; 2003: v. 35, n. 3: p. 159-61.

7-ROSA, W. A. G.; LABATE, R.C. Programa Saúde da Família: a construção de um novo modelo de assistência. Revista Latinoamericana de Enfermagem. 2005: v. 13, n.6: p. 1027-34.

8-SILVEIRA FILHO, A. D. O uso das ferramentas de saúde da família na construção 
do cuidado em saúde. In: ARCHANJO, D. R. et al. Saúde da Família na atenção primária. Curitiba; 2007: p. 101-23.

9-WAGNER, H. L. et al. Trabalhando com famílias em saúde da família. Revista de Atenção Primária à Saúde. Juiz de Fora; 2001: v. 3, n. 8, p.10-4. 